\title{
UMA ANÁLISE ESTATÍSTICA DA ESPIRITUALIDADE ENTRE OS PROFISSIONAIS DA SAÚDE DE UM HOSPITAL DE CURITIBA-PR
}

\section{ENSAIO TEÓRICO}

GERONE, Lucas Guilherme Teztlaff de ${ }^{1}$

NOGAS, Paulo Sergio Macuchen ${ }^{2}$

GERONE, Lucas Guilherme Teztlaff de. NOGAS, Paulo Sergio Macuchen. Uma análise estatística da espiritualidade entre os profissionais da saúde de um Hospital de Curitiba-PR. Revista Científica Multidisciplinar Núcleo do Conhecimento. Ano 05, Ed. 09, Vol. 01, pp. 72-88. Setembro de 2020. ISSN: 2448-0959, Link de acesso: https://www.nucleodoconhecimento.com.br/ciencia-da-religiao/estatistica-daespiritualidade

\section{RESUMO}

Contexto: há ainda poucos estudos que utilizam métodos quantitativos sobre a prática de cuidado entre os profissionais da saúde. Objetivo: Apresentar uma análise estatística sobre a espiritualidade, religiosidade e saúde na prática do cuidado entre Profissionais de saúde. Métodos: Pesquisa quantitativa de tipo survey classificada como descritiva aplicada com 89 profissionais de Saúde. Resultados: A análise

1 Mestre em Teologia pela PUCPR. Possui Especialização em Comportamento Organizacional; Especialização em Neuropsicopedagogia; Especialização em Filosofia e Sociologia; Especialização em Docência do Ensino Superior. MBAs em Administração e Gestão com ênfase na espiritualidade e religiosidade nas empresas. Graduado em Gestão comercial. Bacharelado em Teologia. Possui Licenciatura em Filosofia e Licenciatura em Pedagogia.

2 Doutor em Administração - PPAD-PUCPR (2010), Mestre em Tecnologia - PPGTEUTFPR (2004), Especialista em Metodologia do Ensino Superior (1998), Graduado em Matemática - PUCPR (1994). 
estatística indicou que os profissionais da saúde acreditam na influência da espiritualidade/religiosidade na vida pessoal e na prática do cuidado a pessoa enferma. Considerações: Faz-se necessária a continuidade de novas pesquisas interacadêmicas com diversidade de técnicas estatísticas que contribuam com a análise da influência da espiritualidade e da religiosidade no contexto hospitalar, e na formação dos profissionais da saúde.

Palavras-chave: Espiritualidade, profissional de saúde, cuidado, estatística.

\section{INTRODUÇÃO}

Durante a história da humanidade os temas espiritualidade/religiosidade e saúde estiveram interligados no trabalho dos profissionais da saúde. Nos últimos anos, as pesquisas do campo da saúde constatam que a religião é um fator psicológico e social poderoso, que influencia grandemente a saúde das pessoas (KOENIG, 2012). Para Moreira-Almeida (2010, p. 18), "espiritualidade/religiosidade têm sido objeto de um crescente interesse entre clínicos e pesquisadores na área de saúde”. Apesar deste crescente, Gerone (2017, p.16) em uma revisão de literatura aponta que "há poucos estudos sobre a espiritualidade e religiosidade na prática do cuidado entre profissionais da saúde". Entre estes estudos nota-se que falta uma interdisciplinaridade metodológica entre qualitativo e quantitativo. De um lado, na área da saúde a maior parte dos estudos utiliza o método quantitativo. A medicina possui uma tradição histórica de pesquisa quantitativa e tem dificuldade de aceitar como estudo científico o método qualitativo (TURATO, 2005). A psicologia, frequentemente utiliza escalas quantitativas para validar os estudos qualitativos (BRYMAN; CRAMER, 1990), tais como os estudos sobre o coping[3] religioso/espiritual (PANZINI, 2004).

Do outro lado, nos estudos da e da ciência da religião, o uso do método quantitativo é algo incomum. Na maior parte o objeto central dos estudos teológicos e da religião é abstrato, por exemplo, a fé, o que torna difícil uma quantificação (GERONE, 2017). Todavia, mesmo que a fé não seja quantificada, estudam-se quantitativamente os 
artifícios da fé, como os padrões de comportamento religiosos aos eventos relativos à saúde (LEVIN, 2003).

Nesse estudo, aponta-se o resultado de uma pesquisa quantitativa com o uso da estatística sobre como os profissionais da saúde enxergam a espiritualidade/religiosidade na prática do cuidado hospitalar. Os resultados obtidos na análise fatorial foram interpretados qualitativamente com a aplicação da técnica de análise de conteúdo.

\section{DEFINIÇÕES DAS TERMINOLOGIAS:}

\section{ESPIRITUALIDADE/RELIGIOSIDADE E SAÚDE}

Não se pretende emitir uma noção completa e final sobre espiritualidade/religiosidade e saúde, mas busca-se um panorama dos termos dentro da área da saúde e religiosa.

De um lado, a religiosidade é uma qualidade daquilo que faz parte da religião, entendida a partir de sua etimologia latina, religare, que significa "religação" entre o homem e Deus (DERRIDA, 2000). De acordo com Koenig (2012, p.11), religião é um sistema de crenças e práticas observado por um grupo de pessoas que se apoiam em rituais ou em um conjunto de escrituras e ensinamentos "que reconhecem, idolatram, comunicam-se com ou se aproximam do Sagrado, do Divino, de Deus".

Do outro lado, a espiritualidade é uma dimensão existencial dinâmica, cultivada no espírito, que impulsiona o ser humano consciente em seus conhecimentos e escolhas vitais, e que pode (ou não) estar relacionada à religião (SOUZA, 2013). Para a médica Puchalski (2006, pp. 14-15), espiritualidade é:

busca inerente de cada pessoa do significado e do propósito definitivo da vida. Esse significado pode ser encontrado na religião, mas, muitas vezes pode ser mais amplo do que isso, incluindo a relação com uma figura divina ou com a transcendência, relações com os outros, bem como a espiritualidade encontrada na natureza, na arte e no pensamento racional. Todos esses fatores podem influenciar o modo como os pessoa enferma e os profissionais da saúde percebem a saúde e a doença e como interagem uns com os outros. 
A noção de saúde mais utilizada no meio acadêmico é da OMS, que entende saúde como uma situação de completo bem-estar físico, mental e social. Para Scliar (2007), esta noção busca expressar "uma vida plena". Por isso, Luz (2013) afirma que se acrescentou a dimensão espiritual à noção de saúde, visto que a espiritualidade/religiosidade influencia toda a vida - os valores, os comportamentos, a política, a economia, a cultura, a educação -, os quais se refletem diretamente na noção de saúde.

\section{METODOLOGIA}

A pesquisa foi realizada com 89 profissionais de saúde do Hospital Universitário Evangélico de Curitiba/PR (HUEC), que responderam à pesquisa no período de 21 de março a 30 de junho de 2014.Foi formalmente requerida ao HUEC a assinatura de um termo de consentimento e aprovação para a realização da pesquisa. Também foi requerido a cada participante que assinasse um termo de consentimento livre e esclarecido. Obteve-se o parecer da aprovação do Comitê de Ética em Pesquisa da PUCPR, consubstanciado no no 48582, em 2 de julho de 2012.

Utilizou-se como método a pesquisa quantitativa de tipo survey, classificada como exploratória e descritiva. Trata-se de um questionário com 35 perguntas, sendo 11 perguntas elaboradas em escala nominal e ordinal, 23 perguntas elaboradas em escala de Likert de 5 pontos ("discordo totalmente" a "concordo totalmente"[4] e "totalmente falso" a "totalmente verdadeiro") e, ao final, uma pergunta aberta.

As 35 perguntas foram divididas em cinco seções: seção l - dados sociobiodemográficos; seção II - noções de espiritualidade/religiosidade e o lugar desses conceitos na vida pessoal; seção III - relação entre espiritualidade/religiosidade e saúde; seção IV - coping religioso-espiritual do profissional; e seção $\mathrm{V}$ - integração da religiosidade e da espiritualidade no cuidado com o paciente. Nesta última seção, a pergunta 35 , por ser aberta, permitiu aos profissionais da saúde relatar suas experiências de integração da 
espiritualidade/religiosidade na prática de cuidados em saúde. Para uma melhor compreensão dos relatos obtidos, utiliza-se o método de análise de conteúdo:

A análise de conteúdo é "um conjunto de técnicas de análise das comunicações visando a obter, por procedimentos sistemáticos e objetivos de descrição do conteúdo das mensagens, indicadores (quantitativos ou não) que permitam a inferência de conhecimentos relativos às condições de produção/recepção (variáveis inferidas) destas mensagens" (BARDIN, 2011, p. 47).

As cinco seções do questionário foram elaboradas visando investigar o porquê e o como ocorre a integração da espiritualidade/religiosidade na prática do cuidado aos pessoa enferma entre os profissionais da saúde e pastoralistas. Portanto, cada seção possibilita uma discussão sobre o tema deste estudo.

O questionário foi elaborado e aplicado via Qualtrics. De acordo com Nogas (2011), Qualtrics é uma plataforma (software) que permite aos usuários criar seus questionários em ambiente web. Uma vantagem importante do questionário on-line é o fato de evitar consumo de papel. Utilizou-se um link de acesso da web que remetia ao questionário e foi enviado aos e-mails dos profissionais da saúde. Assim, cada resposta inserida passou a alimentar automaticamente a base de dados, evitando o consumo de papel, sem a necessidade de digitação posterior, conferência, o que elimina a possibilidade de ocorrência de erros neste processo.

Os dados coletados pela Plataforma Qualtrics de gestão de questionários online, foram exportados e analisados no Statistical Package for the Social Sciences (SPSS), um programa de computador que permite análises estatísticas elementares e avançadas, como métodos multivariados, de forma rápida, tornando a interpretação conveniente para um usuário casual ou experiente (PEREIRA, 2006).

\subsection{CRITÉRIOS DA COLETA DE DADOS}

Como se trata de um estudo exploratório optou-se por trabalhar com uma amostra que representasse no mínimo 10\%[5] dos profissionais de cada uma das classes de 
profissionais da saúde do HUEC. Na obtenção da amostra calculada com tamanho um e meio $(1,5)$ considerou-se o tamanho dois $(2)$.

Em determinas profissões pesquisadas obteve-se a amostra de população maior que $10 \%$, por isso, aponta-se a quantidade de amostra coletada e o percentual representativo dentro da população total: 2 psicólogos/as representam $20 \%$ do total desta população; 63 enfermeiros/a ou técnicos/a em enfermagem, representam 10\% do total desta população; 4 assistentes sociais representam $66 \%$ do total desta população; 3 fisioterapeutas representam $75 \%$ do total desta população; 3 fonoaudiólogos/as representam $100 \%$ do total desta população; 5 farmacêuticos/as representam $20 \%$ do total desta população; 2 nutricionistas clínicos representam $33 \%$ do total desta população; 3 capelães/pastoralistas representam $23 \%$ do total desta população; 5 médicos contratados representam 11\% do total desta população (não se incluiu na amostra os médicos residentes, por serem terceirizados e o HUEC não ter a quantidade exata destes profissionais; portanto, a amostra concentra-se nos médicos contratados).

Foi desconsidera a resposta de um profissional que assinalou a mesma alternativa em todas as perguntas desde a 13 até a 34 e na pergunta aberta relatou não ter interesse em responder. Restaram assim 89 respostas consideradas válidas para a análise.

\section{ANÁLISE EXPLORATÓRIA E RESULTADOS ESTATÍSTICOS}

As análises são resultantes da amostra de 89 participantes. Para identificar a pergunta em discussão no texto, utiliza-se a letra maiúscula $\mathrm{P}$ e o número da pergunta entre parênteses, de acordo com as seções do questionário — por exemplo: (P10).[6]

Os resultados são apresentados de acordo com as cinco seções dos questionários. No primeiro tópico são descritos os dados sociobiodemográficos dos profissionais da saúde, que corresponde às perguntas 1 a 11 . No segundo tópico, discutem-se as práticas religiosas, as noções de espiritualidade/religiosidade e do coping religioso/espiritual para os profissionais da saúde, o que corresponde às perguntas 12 a 18 e 25 a 27. Por fim, no terceiro tópico, aborda-se a relação entre RC: 58335

Disponível em: https://www.nucleodoconhecimento.com.br/ciencia-da-religiao/estatistica-daespiritualidade 
espiritualidade/religiosidade e saúde e a sua integração no cuidado a pessoa enferma, o que corresponde às perguntas 19 a 24 e 28 a 34.

\subsection{DADOS SOCIOBIODEMOGRÁFICOS DOS PROFISSIONAIS DA SAÚDE}

A maior parte dos profissionais da saúde, 74, é do sexo feminino (83\%). Em relação à idade, 43 possuem entre 26 e 35 anos (48\%), 31 têm entre 36 e 40 anos ou acima disto (35\%) e 15 possuem de 21 a 25 anos (17\%) (P02). Sobre os níveis de escolaridade, 36 possuem o superior completo (40\%) e 50 pós-graduação (especialização/mestrado/doutorado) (56\%) (P03). Em relação ao tempo de atuação profissional na área da saúde, 41 possuem de 0 a 5 anos (46\%), 21 de 6 a 10 anos (23\%) e 27 de 11 a 20 anos ou acima disto (30\%) (P06).

Ao perguntar aos profissionais da saúde sobre a sua afiliação religiosa, as respostas foram as seguintes:

Gráfico 1- Afiliação religiosa dos profissionais da saúde

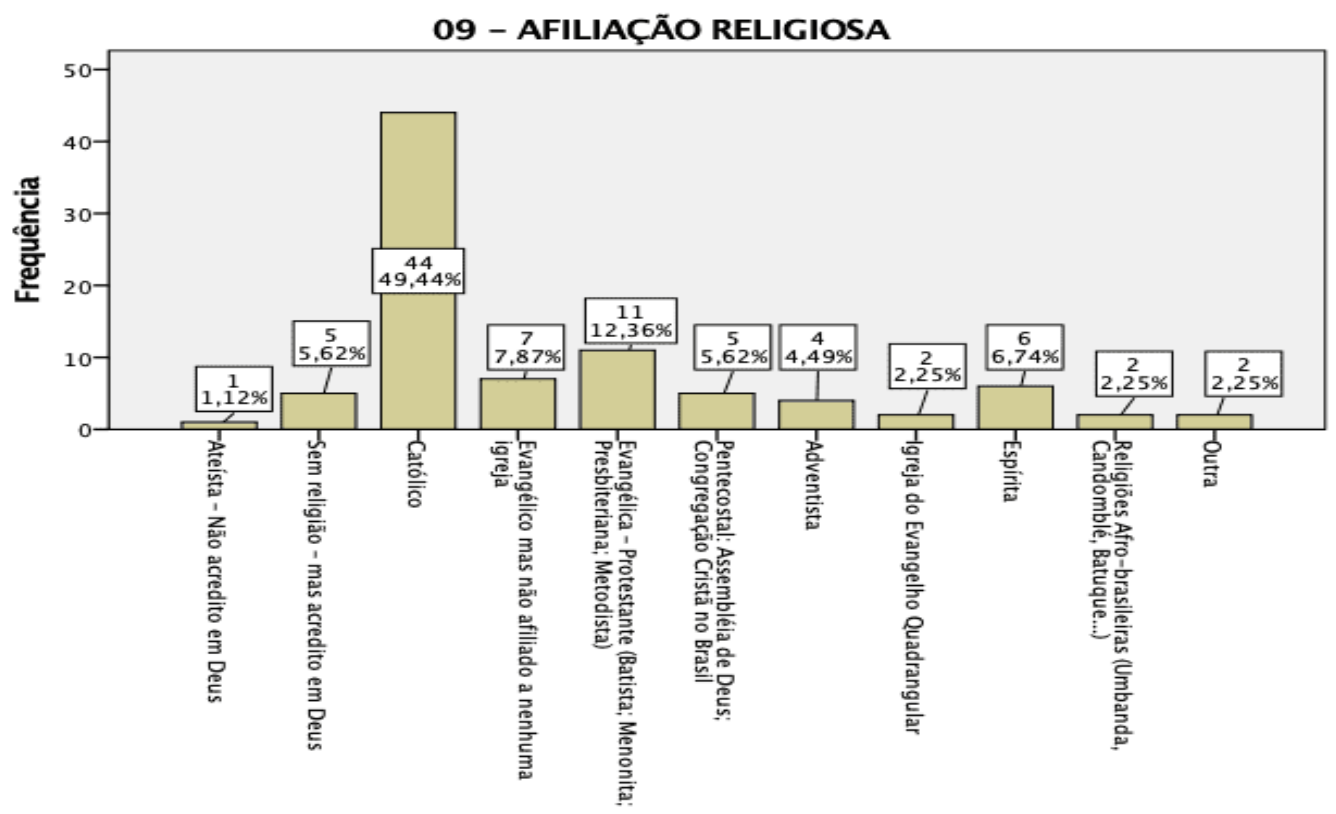

Fonte: autor. 


\subsection{AS PRÁtICAS RELIGIOSAS, AS NOÇÕES DE} ESPIRITUALIDADE/RELIGIOSIDADE E DO COPING RELIGIOSO/ESPIRITUAL PARA OS PROFISSIONAIS DA SAÚDE

Diante dos resultados, 76 (85\%) dos profissionais da saúde são cristãos: 44 católicos (49\%) e 32 protestantes ou evangélicos (36\%) (P09). Dados do IBGE referentes ao Censo de 2010 sobre a religião divulgam que $86,8 \%$ da população brasileira é composta de cristãos, com 64,6\% católicos e 22,2\% evangélicos (AZEVEDO, 2012).

Mesmo que a maioria dos profissionais seja cristã, de um lado, poucos deles frequentam semanalmente uma igreja ou templo religioso. De outro lado, a crença cristã dos profissionais da saúde pode ser um dos motivos de alguns resultados estarem acima da metade das respostas ou em alta, dado que:

Gráfico 2 - A prática religiosa dos profissionais da saúde

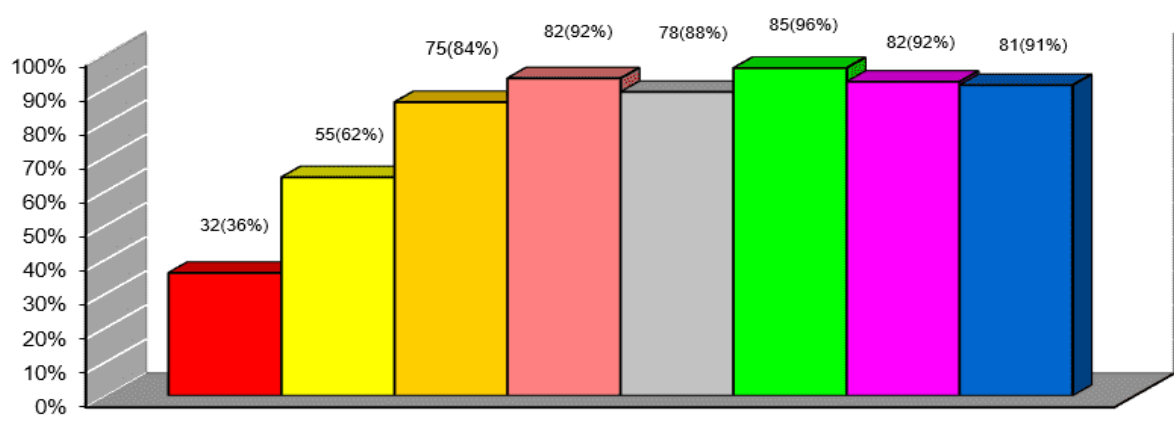

Questões

$\square$ frequentam semanalmente uma igreja ou templo religioso(P10)
$\square$ demonstraram que realizam práticas de meditações e orações individuais, fazendo-as uma ou mais
vezes ao dia (P11)
$\square$ dizem ser verdadeiro viver de acordo com as suas crenças religiosas (P14)
$\square$ dizem ser verdadeiro que as orações, as rezas e as meditações individuais são tão importantes quanto
aquelas feitas em um grupo religioso (P12)
$\square$ dizem ser verdadeiro que é importante ter um tempo privado para fazer meditações e orações
pessoais (P13)
$\square$ dizem ser verdadeiro que a religiosidade/espiritualidade ajuda a lidar com o sofrimento ou as
dificuldades da vida (P25)
$\square$ dizem ser verdadeiro que frequentemente utilizam as crenças religiosas/espirituais para lidar com
situações difíceis na vida (P26)
$\square$ dizem ser verdadeiro que a oração/reza é uma prática utilizada quando enfrentam problemas no
trabalho (P27)

Fonte: autor.

RC: 58335

Disponível em: https://www.nucleodoconhecimento.com.br/ciencia-da-religiao/estatistica-daespiritualidade 
A questão da baixa frequência dos profissionais a uma igreja ou templo religioso com o fato de a maioria destes profissionais ser cristã e dar importância para a crença e as práticas religiosas de forma individual, como o uso do coping para enfrentar as situações adversas da vida, considera-se que os profissionais da saúde possuem uma religiosidade individual. De acordo com Koenig, a religiosidade individual, também conhecida como religiosidade não organizacional:

refere-se à atividade religiosa que é realizada a sós e em particular, como orar, ou se comunicar com Deus em casa, meditar, ler escrituras religiosas, assistir a programas de televisão religiosos, escutar rádios religiosos, ou realizar rituais privados, como acender velas, usar acessórios religiosos e assim por diante (KOENIG, 2012, p. 11).

A noção alcunhada por Koenig sobre uma religiosidade individual ou não organizacional mantém o religare com o sagrado, com Deus e as práticas religiosas, como orações, meditações e outras, porém, sem a necessidade da participação direta ou a frequência a uma igreja ou templo religioso. Para Teixeira (2005), esta religiosidade "sem religião" é composta por pessoas não adeptas da religião organizacional, que preferem ter uma experiência religiosa independente do sistema religioso tradicional.

Por esta razão, muitas vezes este conceito de religiosidade individual/não organizacional é associado ao conceito de espiritualidade. Todavia, para Koenig (2012), é comum em pesquisas a conexão entre espiritualidade e religião. Nesse sentido, há uma conexão entre os conceitos de religiosidade individual e de espiritualidade na pesquisa feita com os profissionais da saúde do HUEC. Confirmase isto por meio da proximidade do percentual sobre a importância das práticas religiosas individuais e de se ter um tempo privado para praticá-las, e dos altos níveis da importância da espiritualidade, em que: (a) 79 profissionais (88\%) dizem ser verdadeiro que a espiritualidade é importante para uma vida equilibrada e estável, do mesmo modo como a cidadania e as amizades (P16); e 86 (b) profissionais (97\%) dizem ser verdadeiro sentir a presença divina (ou do sagrado, de uma energia cósmica, de um ser superior, de Deus, do Espírito Santo ou de algo maior que eu) (P17). 
Diante dos resultados apresentados, é necessário relacioná-los à questão da integração da espiritualidade/religiosidade na prática do cuidado a pessoa enferma entre os profissionais da saúde, portanto:

a) O fato de os profissionais da saúde dar importância à sua espiritualidade/religiosidade favorece a compreensão de que a espiritualidade/religiosidade da pessoa enferma é fundamental para tratamento. Assim como os profissionais da saúde compreendem que a sua espiritualidade/religiosidade influencia o modo de enfrentamento das adversidades no ambiente de trabalho, também compreendem a presença da espiritualidade/religiosidade dos pessoa enferma no tratamento.

b) A maioria dos profissionais ser cristã facilita o diálogo sobre a importância de integrar a espiritualidade/religiosidade no cuidado a pessoa enferma. Na religião cristã o cuidado dos necessitados ou enfermos faz parte da crença religiosa: "Quando te vimos enfermo, ou na prisão, e fomos visitar-te? E responder-Ihes-á o Rei: Em verdade vos digo que, sempre que o fizestes a um destes meus irmãos, mesmo dos mais pequeninos, a mim o fizestes" (Mateus 25:39-40). Também se encontra uma prática de um cuidado integral do ser humano, espírito, alma e corpo: "E o mesmo Deus de paz vos santifique em tudo; e todo o vosso espírito, e alma, e corpo, sejam plenamente conservados irrepreensíveis para a vinda de nosso Senhor Jesus Cristo" (1 Tessalonicenses 5:23).

Neste sentido, para os profissionais da saúde cristãos, a integração da espiritualidade/religiosidade na prática do cuidado trata de uma testificação dos seus valores religiosos.

\subsection{A RELAÇÃO ENTRE ESPIRITUALIDADE/RELIGIOSIDADE E SAÚDE E A SUA INTEGRAÇÃO NO CUIDADO A PESSOA ENFERMA}

Observa-se que há fortes indícios de relação entre espiritualidade/religiosidade e saúde para os profissionais da saúde do HUEC: (a) 85 profissionais (95\%) concordam 
que os problemas de saúde fazem com que as pessoas se voltem para a religião, portanto, quase todos os profissionais vivenciaram situação que em meio aos problemas de saúde, há uma relação entre a religiosidade e saúde (P19). Sobre esta relação: (b) 65 profissionais (73\%) concordam que determinadas práticas religiosas interferem negativamente no tratamento de saúde (P20), por exemplo, quando o paciente recusa o tratamento médico por causa da sua religião. Quando a espiritualidade/religiosidade é bem empregada no tratamento médico, quase todos os profissionais da saúde acreditam que há uma relação positiva entre espiritualidade/religiosidade no tratamento do paciente: (a) 84 profissionais (94\%) concordam que a religiosidade do paciente (como oração, reza, meditação, frequência a um grupo religioso) coopera no tratamento (P21); e (b) 84 profissionais (94\%) concordam que a espiritualidade do paciente tem influência positiva em seu tratamento (P22).

Apesar dos profissionais da saúde outorgarem alta veracidade que as práticas religiosas e a espiritualidade são positivas para o tratamento, não há alta veracidade ao abordar o tema da integração da espiritualidade/religiosidade no tratamento envolvendo diretamente as práticas dos profissionais da saúde. Ao perguntar (P29) aos 89 profissionais se as pessoas enfermas gostariam de trazer a questão religiosa/espiritual para o tratamento, o percentual de concordância se aproxima de dois terços do total: 
Gráfico 3 - A questão religiosa/espiritual no tratamento

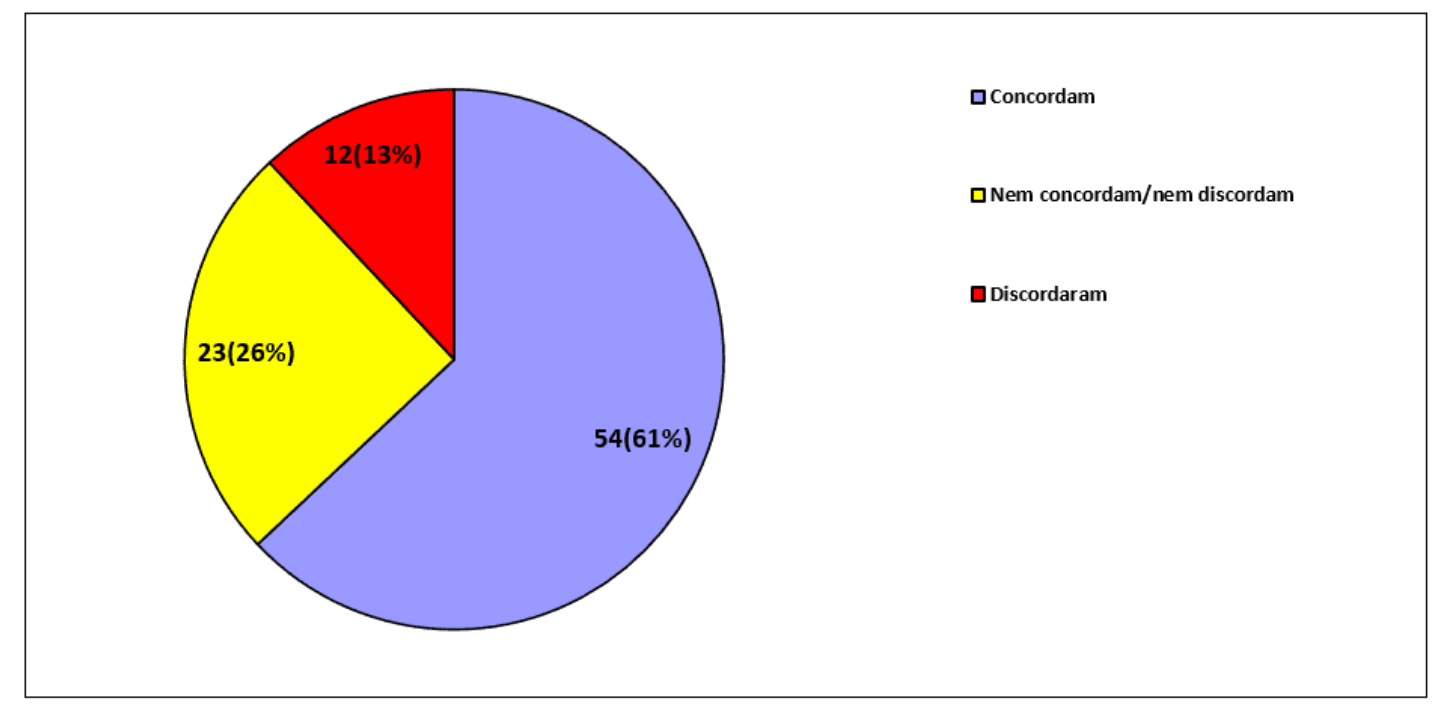

Fonte: autor.

Se os 89 profissionais perguntam frequentemente as pessoas enfermas sobre questões religiosas ou espirituais (P30), há uma forte discrepância nos resultados poucos respondentes neutros, entre os discordantes e os concordantes, somados representam $85 \%$ do total de respondentes, conforme se observa no gráfico abaixo:

Gráfico 4 - As questões religiosas e as pessoas enfermas

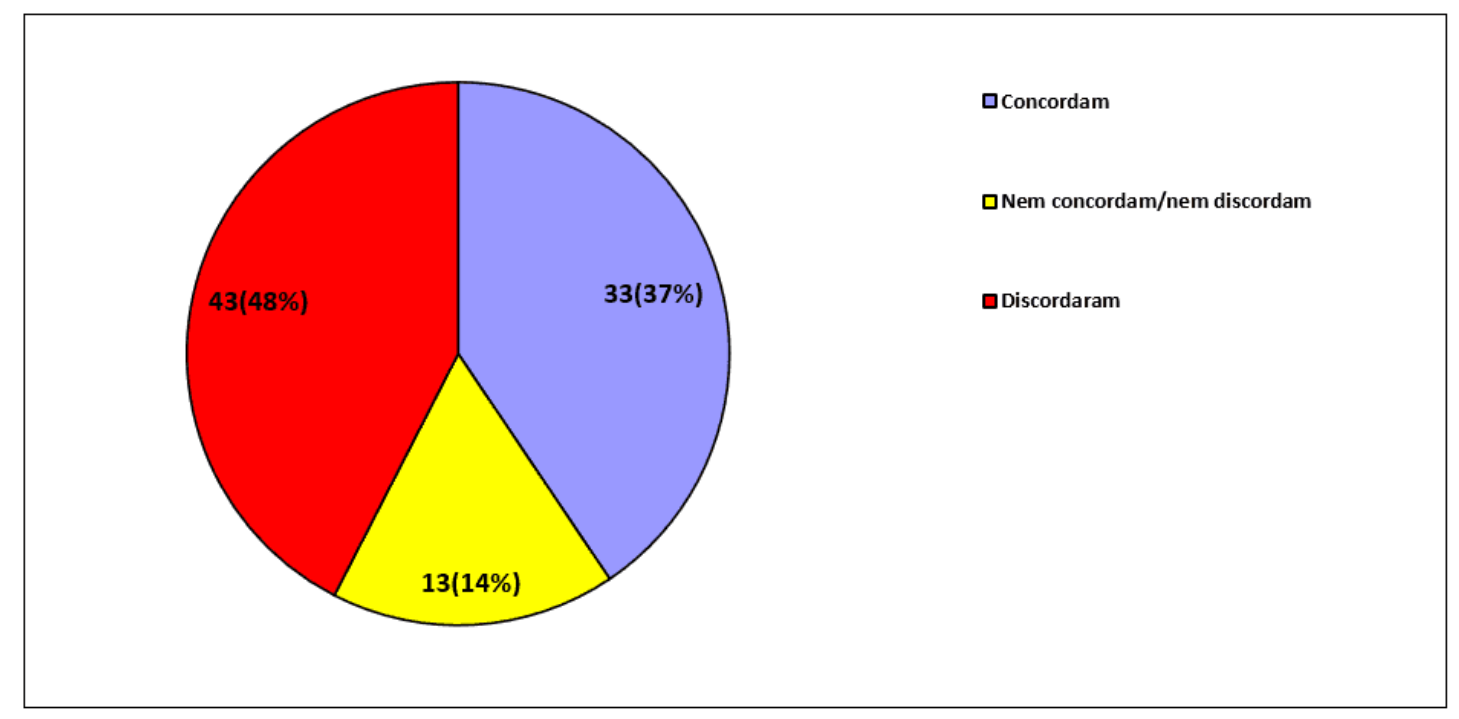

Fonte: autor.

RC: 58335

Disponível em: https://www.nucleodoconhecimento.com.br/ciencia-da-religiao/estatistica-daespiritualidade 
Ao perguntar aos 89 profissionais se eles se sentem confortáveis em abordar a questão religiosa/espiritual durante o processo de tratamento (P32), o percentual de concordância foi preponderante, enquanto os percentuais da discordância e da neutralidade quase empataram:

Gráfico 5 - A abordagem da espiritualidade/religiosidade no tratamento

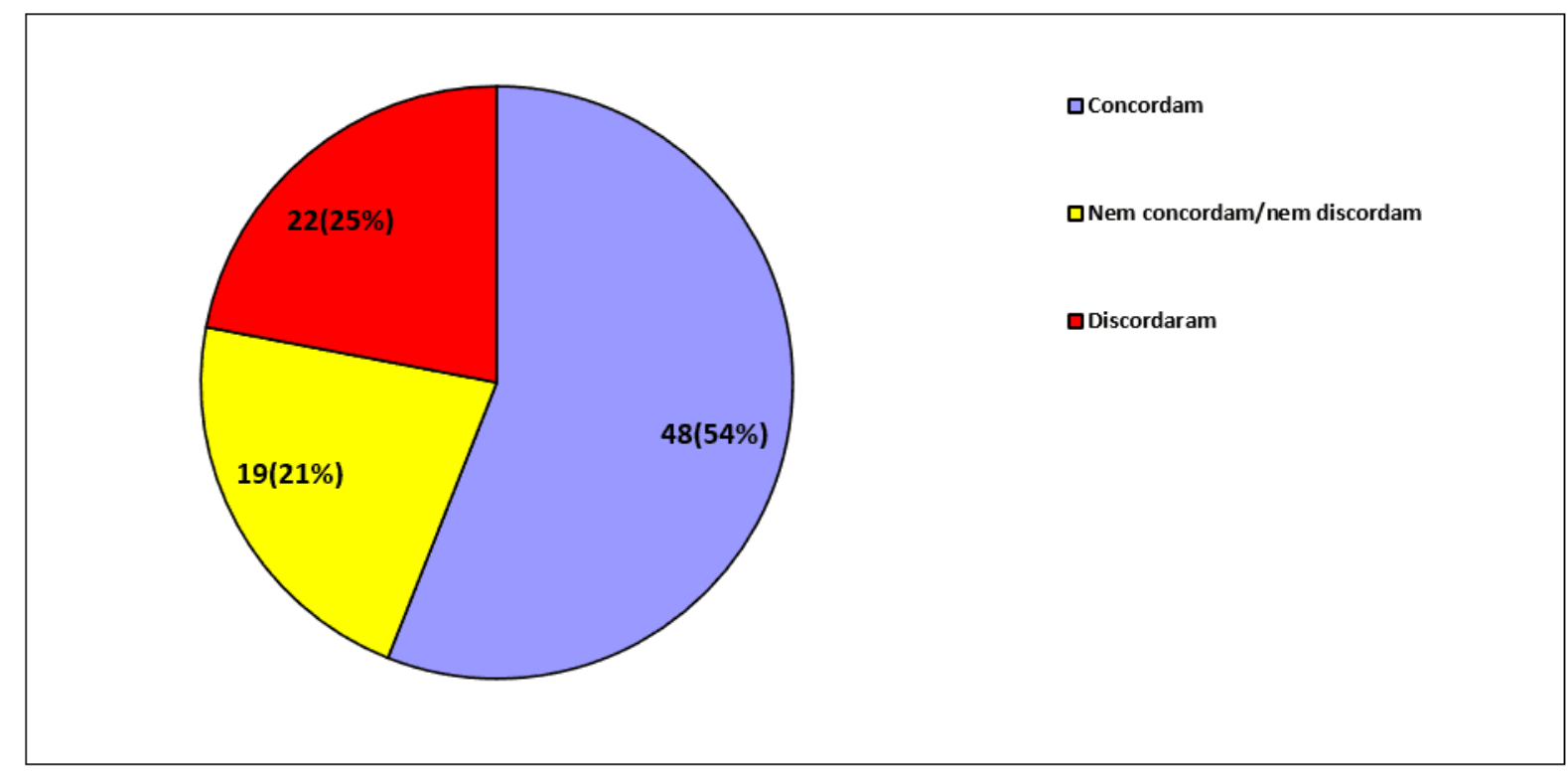

Fonte: autor.

Um dos motivos para que não haja um alto percentual de concordância nestas perguntas (P29, P30 e P32) que envolvem diretamente as práticas dos profissionais na integração de espiritualidade/religiosidade no tratamento das pessoas enfermas está associado à falta de formação em relação à espiritualidade/religiosidade. Entre 89 profissionais da saúde, a maior parte concorda que deveriam receber formação sobre como abordar a questão religiosa/espiritual do paciente durante o tratamento (P31): 
Gráfico 6 - A formação sobre espiritualidade/religiosidade

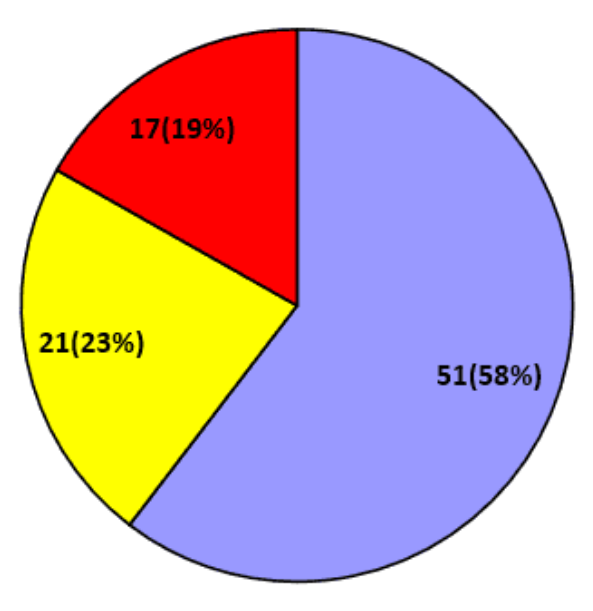

$\square$ Concordam

$\square$ Nem concordam/nem discordam

口Discordaram

Fonte: autor.

\section{CONSIDERAÇÕES}

Depreende-se que as técnicas quantitativas estatísticas aplicadas neste estudo não têm a pretensão de substituir as análises qualitativas. Observou-se uma forte complementaridade entre análise quantitativa e qualitativa - a análise quantitativa confirmou a qualitativa, o que nos faz entender que há uma contribuição significativa à área de estudo da religião. De acordo Gerone (2015) a maioria dos estudos sobre espiritualidade e saúde não utilizam técnicas quantitativas, de modo que o presente trabalho pode ser considerado uma inovação na exploração da temática, tanto na descoberta de dados como na possibilidade de novas pesquisas que envolvam métodos qualitativos e quantitativos.

Essas diferentes abordagens podem proporcionar uma visão ampla sobre espiritualidade e saúde, de um lado, o método quantitativo analisa e extrai dos fenômenos a parte essencial do problema de pesquisa e a solidifica em contexto, por exemplo, as questões sociobiodemográficos dos sujeitos da pesquisa são essenciais para o estudo do fenômeno. Do outro, o método qualitativo tem uma extraordinária 
rica linguagem interpretativa do problema de pesquisa, tais como, o comportamento ou a percepção dos sujeitos da pesquisa.

Especificamente o fenômeno deste estudo: espiritualidade/religiosidade não podem ser quantificadas, todavia, podem-se analisar estatisticamente padrões de comportamentos e crenças dos profissionais da saúde sobre a influência dos fenômenos religiosos e espirituais nos eventos relativos à saúde. Neste contexto, considera-se que a análise estatística deste estudo permite:

a) Mensurar e apresentar com mais precisão os resultados, por meio de indicadores e representações gráficas.

b) Dar confiabilidade e relevância acadêmica à pesquisa, tanto (a) para área da saúde: medicina, enfermagem, psicologia, como (b) para área religiosa: teologia, ciência da religião.

Em segundo momento, sobre a espiritualidade/religiosidade na prática do cuidado entre profissionais da saúde a análise estatística permitiu observar no universo estudado:

a) $99 \%$ possuem uma afiliação religiosa, sendo $85 \%$ profissionais da saúde cristãos. Possivelmente, por isso, a espiritualidade é uma noção que ocorre dentro da religiosidade através de práticas religiosas, tais como, a oração, que aparece no uso do coping para enfrentar as situações adversas da vida e no ambiente de trabalho. $O$ coping religioso espiritual é um recurso positivo para o enfrentamento e resiliência, o que confirma que os profissionais da saúde vêm a religiosidade/espiritualidade como algo mais positivo do que negativo.

b) $94 \%$ concordam que os problemas de saúde fazem com que as pessoas se voltem para a religião, tendo uma relação entre a religiosidade e saúde. Ainda, 93\% dos profissionais da saúde concordam que a espiritualidade do paciente tem influência positiva em seu tratamento. As perguntas sobre o impacto positivo da espiritualidade/religiosidade no tratamento da pessoa enferma são extremamente 
relevantes. A pergunta com a maior relevância refere-se ao efeito positivo da religiosidade (oração, meditação e frequência a um grupo religioso) no tratamento da pessoa enferma. Dentro deste contexto, pode-se depreender que, para os profissionais da saúde, a espiritualidade da pessoa enferma ocorre mediante as práticas religiosas: oração, meditação e frequência a um grupo religioso.

c) Os resultados demonstram notável relação e importância da espiritualidade/religiosidade no contexto de saúde, todavia, os índices estatísticos o caem para $60 \%$ quando perguntando aos profissionais da saúde sentem confortáveis em abordar a questão religiosa/espiritual durante o processo de tratamento. A falta de conforto para lidar com as questões espirituais da pessoa enferma pode estar relacionada à falta de conhecimento sobre as dimensões espiritual e religiosa do paciente. Sobre isto, $65 \%$ dos profissionais da saúde concordam que deveriam receber formação sobre como abordar a questão religiosa/espiritual do paciente durante 0 tratamento. A formação e 0 conhecimento sobre a religiosidade/espiritualidade pode ajudar os profissionais da saúde a reconhecer a necessidade espiritual e religiosa da pessoa enferma e identificar se estes gostariam de trazer isso para o tratamento.

Por fim, diante do observado entende-se que são necessárias novas pesquisas das áreas da religião e da saúde com métodos quantitativos e qualitativos sobre: a influência positiva e negativa da afiliação e crença religiosa dos profissionais da saúde na prática do cuidado a pessoa enferma e na vida pessoal; a influência da oração, meditação e frequência a um grupo religioso no tratamento da pessoa enferma, e como a espiritualidade pode contribuir na formação dos profissionais da saúde.

\section{REFERÊNCIAS}

AZEVEDO, R. "O IBGE e a religião - Cristãos são $86,8 \%$ do Brasil; católicos caem para 64,6\%; evangélicos já são 22,2\%". Disponível em: <http://veja.abril.com.br/blog/reinaldo/geral/o-ibge-e-a-religiao-\%E2\%80\%93- 
cristaos-sao-868-do-brasil-catolicos-caem-para-646-evangelicos-ja-sao-222/>. Acesso em 29 de julho de 2014.

BARDIN, L. Análise de conteúdo. São Paulo: Edições 70, 2011.

BíBLIA DE JERUSALÉM. São Paulo: Paulus, 2002.

BRYMAN, A.; CRAMER. D.Análise de dados em Ciências Sociais:Introdução às técnicas utilizando o SPSS. Oeiras: Celta, 1990.

DAMASIO, Bruno Figueiredo. "Uso da análise fatorial exploratória em psicologia". Aval. Psicol., Itatiba, v. 11, n. 2, 2012. Disponível em $<$ http://pepsic.bvsalud.org/scielo.php?script=sci_arttext\&pid=S167704712012000200007\&lng=pt\&nrm=iso>. Acesso em 23 de setembro de 2014.

DERRIDA, Jacques; VATTIMO, Gianni (orgs.). A religião: o seminário de Capri. São Paulo: Estação Liberdade, 2000.

ESPINOZA, F. da S.; HIRANO, A. S. "Como dimensões de avaliação dos atributos importantes na compra de condicionadores de ar: um estudo aplicado". Rev. Adm. Contemp., Curitiba, v. $7, \quad$ n. 4, 2003. Disponível em $<$ http://www.scielo.br/scielo.php?script=sci_arttext\&pid=S1415$65552003000400006 \&$ Ing=en\&nrm=iso $>$. Acesso em 23 de setembro de 2014.

GERONE, L. A Espiritualidade/religiosidade na prática do cuidado entre os Profissionais da Saúde.Rev. Inteirações Cultura E Comunidade, Belo Horizonte, V.11 N.20, P. 129-151, Jul./Dez. 2016.

GERONE, Lucas Guilherme Teztlaff de. Um olhar sobre a Espiritualidade/religiosidade na Prática do Cuidado entre profissionais de saúde e pastoralistas.Dissertação (Mestrado em Teologia) - Escola de Educação e Humanidades. PontifíciaUniversidadeCatólica do Paraná. Curitiba, 2015. 
GEORGE, D.; MALLERY, P. SPSS for Windows step by step: A simple guide and reference. 11.0 update. Boston: Allyn \& Bacon.

HAIR JR., J. H.; BABIN, B.; MONEY, A. H.; et all. Fundamentos de métodos de pesquisa em administração. Porto Alegre: Bookman, 2005.

KOENIG, H. Medicina, religião e saúde: 0 encontro da ciência e da espiritualidade. Porto Alegre: LMP, 2012.

LEVIN, J. Deus, fé e saúde - explorando a conexão espiritualidade-cura. São Paulo: Cultrix, 2003

LUZ, M. Origem etimológica do termo. Diponivel em: $<$ <ttp://www.epsjv.fiocruz.br/dicionario/verbetes/sau.html>. Acesso em $1^{\circ}$ de outubro de 2013.

MOREIRA-ALMEIDA A, et al. "Envolvimento religioso e fatores sociodemográficos: resultados de um levantamento nacional no Brasil”. Revista de Psiquiatria Clínica v. 37, n. 1, 2010. Disponível em: <http://www.scielo.br/scielo.php?pid=S010160832010000100003\&script=sci_arttext>. Acesso em 29 de setembro de 2013.

PANZINI, R. Escala de coping religioso-espiritual (escala cre). Dissertação de Mestrado em Psicologia. Porto Alegre: Universidade Federal do Rio Grande do Sul, 2004.

PEREIRA, A. Guia prático de utilização do SPSS: Análise de dados para Ciências Sociais e Psicologia. Lisboa: Sílabo, 2006.

PUCHALSKI, C. M. "Espiritualidade e medicina: os currículos na educação médica". JournalofEducation Câncer: O Jornal Oficial da Associação Americana para a Educação do Câncer, 21 (1), pp. 14-18, 2006.

SCLIAR, M. "Histórico do conceito de saúde". PHYSIS: Rev. Saúde Coletiva, Rio de Janeiro, n. 17, v. 1, pp. 29-41, 2007. 
SOUZA, W. "A espiritualidade como fonte sistêmica na Bioética”. Rev. PistisPrax., Teol. Pastor., Curitiba, v. 5, n. 1, pp. 91-121, jan./jun. 2013.

TEIXEIRA, F. "O potencial libertador da espiritualidade e da experiência religiosa". In: AMATUZZI, M. M. Psicologia e espiritualidade. São Paulo: Paulus, 2005.

TURATO, Egberto Ribeiro. "Métodos qualitativos e quantitativos na área da saúde: definições, diferenças e seus objetos de pesquisa”.Rev.Saúde Pública, São Paulo, v. 39, n.3, jun. 2005.Disponível em: <http://www.scielo.br/scielo.php?script=sci_arttext\&pid=S0034$89102005000300025 \&$ Ing=en\&nrm=iso $>$.Acesso em 27 de novembro de 2014.

\section{APÊNDICE - REFERÊNCIAS DE NOTA DE RODAPÉ}

3. O copingé uma palavra derivada do inglês que não possui tradução literal em português, podendo significar "lidar com", "manejar", "enfrentar" ou "adaptar-se a" (PANZINI, 2004, p. 20).

4. Encontra-se dificuldade de interpretação em algumas perguntas com as alternativas de "concordância/discordância"; neste caso, deveria ser em termos de "totalmente falsa/totalmente verdadeira", pois os termos "concordância/discordância" podem dar margem à interpretação de outro tipo de pergunta, que poderia ser "concorda em perguntar".

5. A amostra utilizada neste estudo é pequena, algo que limita os resultados e análise ao grupo estudado, ou seja, não permite extrapolação ou generalização.

6. É possível visualizar todo 0 questionário disponível: http://www.biblioteca.pucpr.br/tede/tde_busca/arquivo.php?codArquivo=3116

Enviado: Agosto, 2020.

Aprovado: Setembro, 2020. 